\title{
Musiek as hulpmiddel in pastorale terapie
}

\author{
J F Maritz \& T F J Dreyer ${ }^{1}$ \\ Departement Praktiese Teologie \\ Universiteit van Pretoria
}

\begin{abstract}
The use of music in pastoral therapy

Both religion and music are ways for a person to express a relationship with God, other people, nature and the self. In the premodern paradigm, the interwoven relationship between human beings, music and religion was seen holistically. The rationalism of the modern era alienated people from this ontological relationship with music. Following the modern era, the current postmodern need for wholeness has resulted in various holistic therapies. This article examines the use of music as a powerful therapeutic resource in pastoral therapy. It argues that music can be used to assist a person as an integrated being. The use of a holistic approach emphasizes the creative responsibility and various possibilities of a life coram Deo.
\end{abstract}

\section{INLEIDING}

Ons het vir julle op die fluite gespeel, maar julle het nie gedans nie! Ons het 'n treurlied gesing, en julle het nie gehuil nie!

(Matt 11:17)

In Matteus 11:16 vra Jesus met wie Hy hierdie geslag moet vergelyk. Daar word deur fluitspel 'n uitnodiging gerig om te dans, daar word deur treurliedere 'n uitnodiging gerig om te huil - maar op hierdie uitnodigings word nie gereageer nie.

\footnotetext{
1 Finansiele bystand van die Nasionale Navorsing Stigting (NRF) word hiermee erken. Opinies wat in hierdie navorsing uitgespreek word en gevolgtrekkings waartoe gekom word, is die van die outeur en nie noodwendig dié van die NRF nie. Die artikel is die eerste deel van die verwerking van J F Maritz se MA Teologie-skripsie. Prof dr T F J Dreyer het gedien as studieleier.
} 
Die uitgangspunt van hierdie artikel is dat musiek en die mens ontologies en epistemologies verbind is. Musiek is deur God as uitdrukkingsmedium aan mense gegee om kreatief met God, die werklikheid, hulleself en hulle medemens om te gaan. In die voormoderne paradigma is die waarde van musiek en die effek daarvan op die mens verreken as deel van 'n holistiese werklikheidsbegrip. Tydens die fragmentasie en rasionalisme van die moderne periode het die mens egter vervreem geraak van die estetiese rasionalitiet. Denkers meen (kyk Rossouw 1993:901) dat die breerr rasionaliteits- en antropologiese beginsels van die postmoderne periode die geleentheid bied om mens en kommunikasievorme soos musiek weer nader aan mekaar te trek. Pastorale terapie as hulpverlening vanuit 'n geloofsperspektief bied ideale geleentheid om die terapeutiese funksie van musiek aan te wend. Dit is ook 'n geleentheid om mense bewrus te maak van hul kreatiewe moontlikhede en geleenthede om in verantwoordelikheid voor God te leef.

\section{DIE POSTMODERNE PARADIGMA}

Daar is vandag bree konsensus in teologiese en filosofiese kringe dat ons ons in 'n postmoderne fase na die moderne bevind (Rossouw 1993:894). Dit het uiteindelik moontlik geword om te kan terugkyk en ons in 'n mate te distansieer van 'n wêreldbeeld wat vir ongeveer vyf eeue toonaangewend was. Die sogenaamde moderne era is natuurlik nie sonder meer onderskeibaar en definieerbaar nie, maar dit word algemeen aanvaar dat dit 'n kombinasie van toenemende ekonomiese en tegnologiese welvaart en vooruitgang was wat die wêreldbeeld en mensbeeld gefragmenteer en verskraal het tot beklemtoning van die rasionele (Van Aarde 1990:293; Van Huyssteen 1996:105). "Die moderne mens verwag dus sy of haar redding van die rede" (Marquard, in Steenkamp 1996:752). Deur objektiewe analise en waarneming was dit moontlik (is geglo) om die werklikheid te ken en te beheer. Die het meegebring dat subjek en objek kenteoreties geskei is. "The subject-object paradigm was judged superior .... because of its potential to produce more sophisticated and more universally valid knowledge" (Rossouw 1993:896).

Hierdie oorskatte vertroue in die mens se rede en kognitiewe vermoe het die mens se verhouding met sigself, ander en die natuur radikaal beïnvloed (Steenkamp 1996:752). Schoeman (1990:268) meen dat die "deelnemende bewussyn" van mens en natuur sedert 
die $16^{\circ}$ en $17^{\circ}$ eeu verander het na 'n "vervreemde bewussyn": "...daar is geen sprake van 'n eksakte versmelting met die naturur nie, maar volstrekte afsondering daarvan voer die botoon." Hierdie verskraalde mensbeeld het tot noodwendige gevolg gehad dat die gevoelsmatige, die metafisiese en estetiese op die agtergrond geskuif het ter wille van die rasionele magsbeheptheid van die subjek. In hierdie era van rasionalisme tree daar dus onder andere 'n vervreemding in tussen mense en hulle essensiële behoefte aan die estetiese uitlewing deur verskillende kunsvorme. Kuns en musiek (en per implikasie emosie) is as ondergeskik aan die rede gestel. "Recognition of music's ... powers is rare in the present rationalism of Western culture. Here music is thought of as one of the 'arts' and thus relegated to areas of life regarded (like religion) as decorative, perhaps enhancing, but inessential" (Wilson-Dickson 1997:13). 'n Wending het egter begin plaasvind en nuwe begrippe soos holisme, spiritualiteit en postmoderniteit het deel van die wetenskapsdiskoers geword. Die postmoderne mens het 'n behoefte en nood na geintegreerdheid en heelheid: "... the thirst for postmodernity is the thirst for a renewed sense of the whole" (Peters, in Van Aarde 1990:300). Van Huyssteen (1996:105) meen tereg dat die intellektuele en spirituele aard van die Westerse kultuur pluralisties [en postmodern] is, maar dat die empiriese wetenskap steeds in 'n groot mate ons kultuur beheer.

'n Belangrike insig van die postmoderne era is dat irrasionaliteit en waarskynlikheid nou erken word as deel van ons werklikheid. Daarom is volledige kennis nie alleen onmoontlik nie, maar altyd subjektief (Van Huyssteen 1996:105). Schoeman (1990:270) meen dat ons "sensuele deelnemers [is] aan dieselfde wêreld wat ons poog om te beskryf." Om tot verstaan te kom (in teenstelling met die moderne eis van om te ken), is nou afhanklik van die subjek se verhouding tot die objek wat mede-subjek word (Steenkamp 1996:753). Die epistemologiese klem lê op die magsvrye relasie tussen subjek en subjek (Dreyer 1998:10). Postmoderne hermeneutiek vra dus om te verstaan eerder as om te ken. Die verbreding van die rasionaliteitsbeginsel stel die pragmatiese, emosionele, estetiese en instrumentele funksies van die mens gelyk aan die rede. "Postmoderniteit wil die pragmatiese en affektiewe dimensies van menswees nás die kognitiewe beklemtoon" (Van Aarde 1995:20). Die postmoderne verskuiwing gee aan die mens geleentheid om multi-dimensioneel te dink, voel, ervaar en tot verstaan te kom.

Die antropologie van die postmoderne era sien mense ingebed in verhoudings wat hulle emosioneel, esteties en rasioneel aanspreek. “...[T]he awareness of humanities 
organic embeddedness in a complex and natural system" (Slater, in Schoeman 1990:278) word weer beklemtoon. Daar is weer klem op die mens as emosionele wese, wat ook nierasioneel kan ervaar en wat oor die moontlikheid beskik om ervaring te transendeer en sin daaruit te maak, ook uit nie-rasionele gevoelens. Om hierdie rede is daar nuwe klem op die invloed wat waardes, simbole en rituele op die mens het (kyk o a Rossouw 1993:900; vgl Steenkamp 1996:755; Van Aarde 1995:43). Die gebruik van simbole, metafore, beelde, rituele, musiek en kuns kan die postmoderne mens begelei na heelword. Die postmoderne insig is dus om die mens weer deelnemer aan die mens se eie werklikheid te maak. Hierdie insig is op 'n bree terrein ook uitgebrei na 'n ekologiese en ekohermeneutiese bewuswording (Müller 1997).

Verskeie modelle en teoriee ontwikkel tans om te voorsien in die toenemende behoefte aan singewing en holistiese groei. Wilson-Dickson (1997:13) formuleer dit soos volg: "Slowly attitudes are changing in the West. Psychologists and psychiatrists, bound as they are by the scientific requirements of objective observation and deduction, are becoming more willing to acknowledge that religious awareness and artistic endeavor may be essential to mental well-being."

In hierdie artikel wil ek aantoon dat musiek kan help om beide die rasionele en emosionele kwaliteite van menswees aan te spreek. Kuns in die algemeen en musiek is besonderlik funksioneel vir die skep van 'n "deelnemende bewussyn" in die hermeneutiese proses en in die herwinning van wat Schoeman (1990:273), in 'n ander verband, die "betowering van die wêreld" noem.

\section{PASTORALE TERAPIE IN 'N POSTMODERNE ERA}

Die vervreemding aan die transendentale wat die gefragmenteerde moderne tydsgees geskep het, het in die postmoderne era oorgegaan na 'n vraag na singewing en outentieke mens-wees voor God. Pastorale terapie is gerig op die konkretisering van God se liefde en trou aan mense in nood - ook die soekende mens na outentisiteit.

\subsection{Omskrywing van die begrip pastorale terapie}

Louw (1997:28) beskryf die doel van pastorale terapie om by die pastorant 'n toestand van heling, verandering en groei as uitvloeisel van die kommunikasie van die 
evangelie/heil te bewerk. "In samehang met die hoop van die Christelike geloof kan pastorale terapie omskryf word as promissioterapie." Vanaf 1960 ontwikkel pastorale terapie tot 'n proses om te voorsien aan 'n geloofsperspektief van hulpverlening. Faber (in Heitink 1984:260) gebruik die term "pastorale terapie" vir die eerste keer. "Met de term pastorale terapie, wil hij uitdrukken, dat deze hulp ooreenkomst met terapie heeft, maar dat het wezenlijke eraan pastoraat is, n.l. mensen te helpen hun leven te zien in vrijheid en uiteindelijk gericht op een leven in het licht van God." As konkrete vorm van die pastoraat maak pastorale terapie van 'n multidissiplinêre benadering gebruik, maar geskied steeds vanuit 'n selfstandige perspektief met 'n eie teologiese bron, metode en doel. Soos in die teologie in die algemeen, gaan dit in die pastoraat spesifiek om die balans tussen teorie en praxis, openbaring en ervaring. Die vraag is in welke mate God se openbaring en in welke mate die mens se nood en omstandighede aan die orde moet kom tydens die pastorale gesprek.

Vir die doel van hierdie studie sou 'n mens die twee pole ook kan omskryf as teologie en antropologie (menslike ervaringswerklikheid). Dit is insiggewend om te sien dat die ontwikkelingsgeskiedenis van pastoraat as ' $t$ ware hierdie spanning tussen teologie en antropologie reflekteer. Die worsteling van pastoraat om "teologie te bly" en "prakties te word" het uitgemond in verskillende modelle. Die kerugmatiese model van Thurneyssen staan waarskynlik die naaste aan die teologies-teoretiese pool. Binne die konteks van die dialektiese teologie is woordverkondiging vir Thurneyssen die praxis van die pastoraat, met vergifnishulp as doel (kyk Heitink 1984:23). Die kritiek op hierdie model is dat die mens se ervaringswêreld nie voldoende verreken word nie (Louw 1997:45). As reaksie hierteen ontwikkel die Amerikaners Boison en Rogers se ervaringsmodel. Hulle stel 'n empatiese, non-direktiewe metode van hulpverlening voor waar die mens en die mens se potensiaal om sigself te verwesenlik, sentraal staan (Heitink 1984:40). Louw (1997:46) meen dat hierdie metode die gevaar inhou dat te veel klem geplaas word op die ervaring, en dat die teologies-teoretiese pool nie voldoende verreken word nie. Heitink (1984) poog om binne 'n bipolêre model altwee pole te verreken. Die trou en beloftes van God word vir mense in konkrete situasies sigbaar. Volgens Heitink (1984:174) is die spanning tussen openbaring en ervaring wesenlik en onophefbaar, maar noodsaaklik en konstruktief vir die dinamika van die pastorale gesprek. Sy uitspraak 
"God bly God" en "mens word mens" som sy teorie op. Louw (1997:88) bied 'n konvergensiemodel in eskatologiese perspektief aan as vierde moontlikheid naas bogenoemde. Hy poog om met die eskatologiese voorbehoud van sy teorie die normatiewe wat in die openbaring van God gelee is, te behou. Verder wil hy verhoed dat "bipolariteit vasval in loutere funksionaliteit en komplimentariteit" (Louw 1997:84).

Vanuit hierdie kort historiese opsomming is dit dus afleibaar dat pastoraat tans in die aanvangsera van postmoderniteit steeds beoefen word met inagneming van sowel teologie (as die refleksie op die normatiewe in die openbaring van God) en antropologie (as die refleksie op die subjektiewe menslike ervaring). Binne hierdie konteks wil pastorale terapie 'n ontmoeting bewerkstellig tussen die mens, in sy of haar situasie van nood en 'n gans Andere God wat medelye met die mens het.

\subsection{Postmoderne perspektiewe}

'n Aantal nuwe perspektiewe oefen ' $n$ invloed uit op die huidige siening van pastoraat as wetenskap. Een daarvan is dat geloof nie kennis alleen is nie, maar ook ervaring naas kennis (Kloppers 1994:584). Geloof bestaan nie uit 'n reeks feitelike waarhede oor God nie. Geloof is ook ervaring en belewenis nass kennis, sodat die gelowige mens in totaliteit aangespreek voel. Die verbreding van rasionaliteit bring die klem op die instrumentele rede van die vorige paradigma weer in balans (kyk Beukes 2000:72-130). Die mens is 'n eenheidswese wat rasioneel, emosioneel en esteties funksioneer. Volgens Heitink (1984:84) is die "hele mens", liggaam, siel en verstand, in dinamiese interaksie.

Tans wớd daar oor die breẽ spektrum van die kerklike handelingsvelde gesoek na wyses om die totale mens aan te spreek. Dreyer (1995:802) pleit vir 'n uitbreiding van geloofshandelinge na alle fasette van kerklike praxis. Wanneer teoloe pleit vir 'n nuwe balans tussen ervaring en rede is dit spesifiek om 'n ongebalanseerdheid (klem op die instrumentele rede) te herstel. "Let wel, handel en gevoel vervang nie die rede nie" (Van Aarde 1995:20).

Die eis om in 'n postmoderne era ook die affektiewe dimensies van menswees in relasie met die kognitiewe te beklemtoon, is teologies gesien 'n welkome vernuwing. Enersyds bevry dit die [verkondiging] van 'n dorre intellektualisme en dogmatisme, maar andersyds, indien die affektiewe in relasie met 
die kognitiewe beklemtoon word, vrywaar dit die [verkondiging] van 'n oppervlakkige emosionaliteit.

(Dreyer 1995:799)

Die erkenning wat ervaring (wat ook die ervaring van die transendente en die metafisiese insluit) in 'n postmoderne era gekry het, het belangrike implikasies vir die Praktiese Teologie as wetenskap. Geloofsvooronderstellings en ervarings word vanuit die perspektief van die nuwe hermeneutiek nie as onwetenskaplik beskou nie. Van Aarde (1994:347) verwys soos volg daarna: "[Die] uitspraak dat daar nie so-iets bestaan as 'vooronderstellinglose' eksegese nie, het met die insig [te doen] dat elke leser van die Bybel sy/haar eie wêreld in die leesproses indra en dat teks en konteks op 'n dialektiese wyse die eksegetiese resultaat beinvloed." Die waarde van postmodeme hermeneutiek is dat erken word dat die Skrif 'n simboliese en metaforiese karakter besit, maar nie allegories uitgelê word soos in die premoderne paradigma nie (vgl Adam 1995:66-68). Louw (1997:110) praat van 'n paradigmaskuif weg van 'n metafisiese verstaan van God (in terme van afstand) na 'n metaforiese verstaan van God (in terme van eksistensiěle kontekste). Louw (s a:16) verwys in hierdie verband na teologie as 'n hermeneutiese en metaforiese wetenskap.

Hierdie ontwikkeling is besig om invloed uit te oefen op die huidige beoefening van Praktiese Teologie. Daar is 'n groeiende besef dat kommunikasie oor God by wyse van simboliese taal geskied. Elsabé Kloppers (1997:322) formuleer dit soos volg: "In die postmodernisme groei die besef dat ons op geen ander manier oor God of oor die werklikheid kan praat, anders as in beelde nie. Dit maak simbole en simboolwêrelde, beelde, verbeelding en metafore toenemend van belang". Vir Louw (1997:111) beteken 'n hermeneutiese model "dat die teologie bewus raak van die metaforiese en simboliese aard van ons spreke oor God". Metafore en simboliese spreke het die verdere funksie dat dit draer is van die paradoks van God: "[m]etaphor always has the character of 'is' and 'is not"' (McFague 1987:33). Wilder (in Kloppers 1994:594) pleit vir 'n poëties-simboliese verstaan van God, wat hy theopoesis noem. Hy meen dat godsdienstige taal in die algemeen gely het onder rasionalistiese vooroordeel. Die vorige denkstruktuur se klem op rasionalisme het dikwels geloofbetuigings verskraal tot woorde. Simboolkommunikasie is in die Protestantse denkklimaat as ' $t$ ware gemarginaliseer. Paul Tillich (in 
Begbie 1991:60) meen dat "the lack of the arts ... in the context of Protestant life is, though historically understandable, systematically untenable and practically regrettable."

\subsection{Kommunikatiewe handelingsteorie}

Op die gebied van die beoefening van Praktiese Teologie in Suid-Afrika is Hennie Pieterse (1993) een van die die teoloe wat 'n voorstander daarvan is dat Jürgen Habermas se kommunikatiewe handelingsteorie as metateorie in die Praktiese Teologie aangewend kan word. Die kern van Pieterse se teorie is dat God handelend met mense werk, wat kommunikasie en handelinge tussen mense - in diens van die evangelie - tot gevolg het. Habermas (kyk Dreyer 1998:33) se taalhandelingsteorie het as doel om magsvrye simmetriese kommunikatiewe interaksie moontlik te maak. Dit word die ideale gespreksituasie genoem. In hierdie verband lewer Kloppers (1997:208-209) 'n belangrike bydrae op die terrein van die liturgiese wetenskap. Sy toon aan dat musiek die geleentheid tot heerservrye kommunikasie bied. Musiek as "kunshandeling” (of nie-verbale kommunikasie) voldoen epistemologies aan die postmoderne eis van 'n magsvrye subjek-subjek relasie. Kloppers (1997) se besondere bydrae bestaan veral daaruit dat sy binne die epistemologiese verwysingsraamwerk van postmodernisme verbande aantoon tussen metaforiese teologie, kerkmusiek, doksologie (kyk later) en kommunikatiewe handelinge. Hierdie studie wil binne dieselfde verwysingsraamwerk die moontlikhede eksploreer dat musiek as hulpmiddel in pastorale terapie benut kan word.

\subsection{Pastorale terapie as kunsvorm}

In pastorale terapie, wat op sigself 'n kreatiewe proses of "kunstige wetenskap" (Muller \& Heine 1998:166) is, behoort 'n mens bewus te raak van al die ander kommunikasiemoontlikhede van menswees. Dingemans (1991:146) praat in hierdie opsig van interaksionele simboolkommunikasie of indirekte kommunikasie waar verskillende sisteme van simbole en tekens in wisselwerking is. Insig breek deur (of daar word tot verstaan gekom) wanneer verskillende verstaanshorisonne versmelt. Poěsie, metafore en simbole, kuns en musiek kan dus 'n ontmoeting tussen God en mens bewerkstellig waar woorde en tegnieke faal. Die terapeut behoort dus sensitief ingestel te wees op die ander moontlikhede binne die terapeutiese proses. 
Kuns (musiek, skilderkuns, drama, ens) beskik oor die unieke vermoe van onmiddellikheid, van deursigtigheid sonder om in woorde te kommunikeer. Daar word reeds in feitlik alle ander vorms van terapiee aandag gegee aan die terapeutiese waarde van verskeie kunsvorms. "Humanistically orientated adjunctive art therapists believe that the whole person can be treated through creative expression (art, dance, drama, music, poetry etc) because creative work is compatible with integrating body, mind, spirit and emotion" (Hunter 1990:55).

\subsection{Die kernmoment in pastorale terapie}

Die kernmoment in terapie is verandering. Volgens Firet (1977) is daar twee dinamiese momente of kragte in pastorale terapie: die hermeneutiese moment in die rigting van verstaan en die agogiese moment in die rigting van verandering. Hierdie aspekte is eintlik geïntegreerd met die vorige gedeelte oor die pole teorie en praxis. In 'n meer praxis-gerigde model sal die hermeneutiese moment sterker beklemtoon word. In 'n teoretiese model (bv dié van Thurneyssen) is die imperatief of agogiese moment sentraal. Dreyer plaas dit in 'n postmoderne tydvak in 'n holistiese perspektief: "Die onderlinge verband en interafhanklikheid van die indikatief, imperatief en beloftes in die [kerugma] is hier [in 'n post-moderne era] van belang, omdat dit in 'n sekere sin die kognitiewe, konatiewe en affektiewe dimensies van menswees reflekteer" (Dreyer 1995:799). Louw verstaan die kernmoment van die pastoraat ook as heling. Hy onderskei egter tussen heil en heling: "[t]ussen heil en heling bestaan daar 'n spanning. Die eskatologiese spanning van die alreeds van die heil en die nog nie van die heil beteken dat heil en heling nie identies is nie. Heil breek deur daar waar genesing (heling) plaasvind" (Louw 1997:79). Met al hierdie perspektiewe in gedagte, verstaan ek pastorale terapie as verandering (tydens die proses van tot verstaan kom), wat heling tot gevolg het.

\subsection{Die doelwit van pastorale terapie}

Dreyer (1981:11) sien die doel van die pastoraat "tot opbou van die gemeente van Christus". Pastoraat begin dus in die gemeente in die vorm van gemeenskap tussen gelowiges. 'n Pastorale gesprek behoort ook weer terug te wys na die gemeenskap van gelowiges, sodat die gemeente die persoon sorgend verder kan ondersteun. Alhoewel 
hierdie kenmerk van pastoraat uiters belangrik is (veral ook in die verbinding van musiek, pastoraat en liturgie), wil ek graag die doel van pastorale terapie anders omskryf.

(Louw 1997:90) sê: "Eskatologie stempel antropologie teleologies gesproke tot doksologie." Ek sluit by Louw se teleitiewe model van hoopterapie in eskatologiese lig aan as ek die uiteindelike doelwit van pastoraat stel as doksologie. Doksologie is om 'n lewe van lof en aanbidding in teenwoordigheid van God se heerlikheid te leef. In die liturgiewetenskap word die term "doksologie" breër verstaan. Doksologie is nie alleen lofprysing nie, maar 'n lewe van lofprysing. Dit is onlosmaaklik met die gemeente en die erediens verbind. Hierdie lewe van lofprysing word gevoed in die erediens en die lofprysende individu keer na die erediens terug. Binne pastorale konteks het hierdie lewe van lofprysing bepaalde implikasies. Dit beklemtoon die verantwoordelikheid van elke gelowige om in elke nuwe situasie 'n eksistensięle keuse te maak om tot "eer van God coram Deo te lewe" (Dreyer 1998:306). Dit impliseer dat die mens te midde van hopeloosheid en uitsigloosheid, pyn en moedeloosheid die genade van God kan aanvaar en ervaar (kyk Hab 3:17-19; Hand 16:25). Volgens Brueggemann (in Kloppers 1997: 164 ) is doksologie "an act of hope. It promises and anticipates a hoped-for world that is beyond present reality". Dit impliseer 'n geïntegreerde lewe voor God wat vrae en pyn kan omvat, maar wat te midde van reddeloosheid hoop op en glo in God wat reeds gered het. Lof is immers die offer wat God van ons vra (Ps 50:14). Lofprysing word nie net in woorde uitgedruk nie, maar kan ook swye, verwondering en gewaarwordinge van ontsag omvat. "Die voortdurende poging om die menslike spreke te corskrei in die aangesig van God, loop uit op die swye as lof" (Kloppers 1997:164). Wanneer ek 'n lewe van lofprysing as doelwit vir die pastoraat voorstel, word alle moontlike handelinge en kommunikasie daardeur gestempel. Dit sluit ook die nie-verbale gevoelens, handelinge en stilswyes in as aktief lofprysend voor God. Kloppers (1997:164) formuleer dit soos volg: "Doksologie is in wese handeling, gebeure, werklikheidsveranderde gebeure, skeppende gebeure, ontmoetingsgebeure, verkondigingsgebeure en antwoordgebeure dit is reaksie op God se heilshandelinge."

'n Lewe van lofprysing beklemtoon nie net die verhouding tussen mens en God nie, maar beklemtoon ook wat genoem kan word die "essensie van kreatiwiteit." Die Bybel vertel dat God Skepper is; in ontologiese sin beteken dit dat God se wese kreatief 
is. Mense weer is kreatief omdat hulle na die beeld van God geskape is. Kreatiwiteit in die lewe van die mens beteken om die gawes wat God gegee het, te ontwikkel en uit te leef. Volgens Johannson (1984:15) is kreatiwiteit om met integriteit en verbeelding te skep en te onderhou. "Man creates as a result of the responsibility cast upon him in the creation mandate. Formed by God, every man is given the task of responding to his call, to be a co-creator we are to be creative as God is creative." Louw (1997:193) omskryf die term verantwoordelikheid in hierdie verband etimologies: "[r]esponsibility" is in essensie om te "respond to your ability." Hierdie verantwoordelikheid strek vir Louw ook wyer na ekologiese verantwoordingsbewuswording.

Mense behoort dus pastoraal bewus gemaak te word van hulle kreatiwiteit as opgawe en verantwoordelikheid teenoor God, medemens en wêreld. Vanselfsprekend behoort die grondhouding van die pastor te spreek van kreatiwiteit, integriteit en verbeelding. "Die terapeut (kunstenaar) se taak is dan om die kliënt (mede-kunstenaars) te help om die onbekende bekend te maak" (Müller \& Heine 1998:166). Elke mens beskik oor die godgegewe vermoe̊ om met integriteit, verbeelding en verantwoordelikheid op God se genade te reageer, om in kreatiwiteit 'n lewe voor God te leef - in pyn en nood; in lof en aanbidding.

Terapie (as verandering en tot verstaan kom) kan in die pastoraat dus ' $n$ beweging na 'n lewe van lofprysing wees. 'n Definisie vir pastorale terapie sou dus kon lui: Geloofshulp as lewenshulp (Louw 1997:58) vanuit 'n perspektief van hoop, met die essensie om te verander en tot verstaan te kom, doksologies gerig.

In hierdie artikel wil ek die kreatiewe verantwoordelikheid van en opdrag aan die mens wat voor God staan, beklemtoon. Hierdie opgawe aan mense om God kreatief te ontmoet en te verheerlik, ook om kreatief met hulle pyn en vrae voor God te kom staan, kan in pastorale terapie met musiek as hulpmiddel gefasiliteer word. Die kommunikatiewe handelinge binne die pastoraat kan uitgebrei word om mense te begelei om geïntegreerd en lofprysend voor God te staan. Die uitnodiging wat God rig, is een van volheid. God raak ons aan op alle vlakke en moontlikhede van menswees. Ons antwoord aan God en ontmoeting met God behoort ook die volheid en totaliteit van ons menswees te omvat. 


\section{MUSIEK AS UITDRUKKING, KOMMUNIKASIE EN TE- RAPIE}

Die moontlikheid dat die mens iets van sigself deur musiek kan uitdruk, om musiek te waardeer of om die werklikheid te ervaar deur musiek, is uniek aan menswees. Teologies gesien, is die mens kreatief soos wat God kreatief is, omdat die mens na die beeld van God geskape is. Volgens Johannson (1988:18) is kreatiwiteit die imperatief van die imago Dei: "To be God means to be creative, to be human likewise means to be creative". Musiek is 'n medium wat God gegee het waardeur ons ons kreatiwiteit in verhouding met God en met mekaar kan uitleef. Musiek is 'n essensiele antroplogiese uitdrukkingsmedium wat die mens kan begelei tot 'n "deelnemende bewussyn" met die mens self, ander en die natuur. Die moontlikheid wat musiek bied om in beweging te kom, kan nuwe perspektiewe open. Dit kan lei tot verstaan kom en tot verandering. Die hipotese van hierdie studie is dat die moderne era met die verskraalde antropologiese klem op die kognitiewe dimensie van resionaliteit die mens vervreem het van hierdie uitdrukkingsmoontlikheid.

Dit is natuurlik nie so maklik en eenvoudig om die betekenis en affek van musiek op die mens te beskryf nie. Filosowe, komponiste en skrywers worstel trouens al eeue met die vraag. McLaughlin (1970:17) verwys soos volg daarna: "The 'emotions' expressed by music are not easy to translate into any other form, and harder still to define: and they have depths which do not seem to be expressed properly by any other art and by words least of all." Van Schalkwyk (1998) hanteer hierdie komplekse saak vanuit 'n holistiese perspektief wat sy 'n "sisteemparadigma" noem. Volgens haar is mense en musiek ontologies en epistemologies verbind binne 'n geheelsisteem. Sy toon aan dat 'n meganistiese benadering wat die affek van musiek volgens 'n deterministiese en liniêre oorsaak-gevolg paradigma ondersoek en beskryf, nog nooit werklik kon deurdring na 'n beskrywing en verklaring van die interafhanklike verweefdheid en wederkerige prosesse en verandering wat in mens-musieksisteme ter sake is nie. Sy meen dat waarde-oordele (goeie/slegte musiek) steeds die belangrikste argument is wanneer oor die invloed van musiek op die mens gepraat word. Hierdie beskouing is gegrond op 'n rasionele en logies-positivistiese wetenskapsideaal. Alle vorige pogings om die veelvuldige verhoudingspatroon tussen mens en musiek te omskryf is beperk deur hierdie metode. Sy neem 
dan die sisteemteorie as uitgangspunt, waarvolgens die sisteme mens, musiek en die mens-musieksisteem, geheelsisteme met ontluikende eienskappe is. Daarvolgens kan die aard, interaksie, ervarings ensovoorts van hierdie sisteme beskryf word.

\subsection{Historiese oorsig oor die verhouding tussen mens en musiek}

Vir die doel van hierdie studie word daar volstaan met 'n kort oorsig oor die verhouding tuseen mens en musiek oor eeue heen. Vanuit hierdie oorsig sal die vervreemding wat daar in modernistiese paradigma ingetree het tussen mens en musiek, wat die vraag na die outentisiteit van mens-wees betref, ook duidelik blyk. Dit is egter histories nie moontlik om vas te stel hoe of wanneer musiek as menslike kunshandeling presies ontstaan het nie. Daar bestaan baie teorië wat die ontstaan van musiek probeer verklaar. Een so 'n teorie (wat fokus op die twee dimensies: kognitiewe rasionaliteit en estetiese rasionaliteit) is dié van John Blacking in Storr (1992:16):

It is not unreasonable to speculate that speech and music have descended from a common origin in a primitive language which was neither speaking nor singing, but something of both. Later this primeval language would have split into different branches; music would have retained the articulation mainly by pitch (scale) and duration (rhythm), while language chose the articulation mainly by tone color (vowels and consonants). Language moreover happened to become the vehicle of rational thought and so underwent further influences. Music has become a symbolic language of the unconscious mind whose symbolism we shall never be able to fathom.

Histories is dit egter moontlik om vas te stel dat musiek vanaf die vroegste tye onlosmaaklik verweef was met sosiale interaksie van mens-wees. In primitiewe kulture waar musiek vandag nog 'n integrale deel van elke dag is, begelei musiek alle aktiwiteite en bedrywighede van die gemeenskap en individue. Musiek is onlosmaaklik deel van 'n persoon se ervaring van die werklikheid. "...[E]ven songs, as a rule, are not composed simply to be listened to for pleasure. They have work to do, to serve as funeral dirges, as accompaniments to dancing, or to serenade a lover" (Storr 1992:17). 
Vanuit die Bybel leer ons dat mense bepaalde gebeurtenisse asook lof en aanbidding aan God in musiek ervaar het (kyk Strydom 1994b:9-23). Daar is feitlik geen gebeurtenis denkbaar - tensy swye meer gepas was - waar die Bybelse mens nie gemusiseer het nie. Wanhoop en moedeloosheid, intense vreugde en dankbaarheid, rou en droefenis, oorlog en oorwinning is met snarespel, fluitspel, trompetgeskal begelei of in liedere verklank.

Ook die antieke Grieke se geïntegreerde denke word geillustreer in hulle musiekbeskouing. Volgens Phythagoras was die getalleverhouding tussen die hemelliggame dieselfde as dié tussen die toonintervalle van musiek. "Oor musiek word dus kosmologies gedink, en oor die kosmos in terme van harmonie" (Strydom 1994a:6). Plato (in Storr 1992:43) se cortuiging dat "....when modes of music change, the laws of the state always change with them," word eeue later gereflekteer in sosiale sensuur (in die vorm van sosiale realisme) in onder andere Soviet Rusland en Nazi Duitsland (kyk Maritz 1989:33).

Tot met die Aufklärung was daar dus tussen mense, musiek en werklikheid 'n vorm van "deelnemende bewussyn". Musiek was 'n essensiële moontlikheid van die mens om die werklikheid te ervaar, daaroor te dink en dit te verstaan. Die opkoms van die humanisme en individualisme van die Verligting vanaf die $1 T^{\circ}$ eeu (wat ook aangedui kan word as die paradigmaskuif van die premoderne na die moderne) bring 'n nuwe werklikheids- en gepaardgaande kunsbeskouing. Die kunstenaar as individu word die fokuspunt. Die komponis staan nie meer in diens van die kerk of gemeenskap nie, maar skep "kuns ter wille van die kuns" self (Strydom 1994a:104). In hierdie konteks kry kuns 'n kultuurkritiese funksie. Politoske (1984:253) verwys soos volg daama: “Artists became severe critics of society and its institutions. As a result, art seemed to oppose what it once served - the class structure." 'n Breuk ontstaan tussen die Westerse kunskultuur en die gewone volk. "Kuns ter wille van kuns" maak van musiek dus 'n uitgesonderde aangeleentheid vir die intellektueles en ingewydes. "Skoonheid is in die elitistiese kunsgemeenskap ontdaan van alle transendente en Christelik-teologiese assosiasies" (Strydom 1994a:28). Aan die ander kant ontwikkel 'n "unsophisticated, sentimental public that valued art primarily as entertainment" (Politoske 1984:254). In Schoeman (1990) se terme sou ons dus kon sê dat daar 'n "vervreemde bewussyn" 
ingetree het. Deel van die rasionalisme en 'n gefragmenteerde leefwyse van die moderne paradigma is hierdie verwydering tussen mens en musiek as eksistensiěle uitdrukkingsmedium. Musiek verloor die "Verbindung zum Allstag" (Herbst, in Strydom 1994a:31). Musiek wil bloot vermaak of waardeer word, in plaas daarvan om 'n inherente deel van die mens in totaliteit te wees. As gevolg van hierdie verwydering word die affek van musiek op die mens onderskat en onderbeklemtoon. "The idea that music is so powerful that it can affect both individuals and the state for good or ill has disappeared. In a culture dominated by the visual and the verbal, the significance of music is perplexing, and is therefore underestimated" (Storr 1992:xii).

'n Marxisties-sosialistiese siening hieroor is dat "music [is] used by bourgeois society mainly as creation, for the reproduction (re-creation) of labour power, to lull people and to blunt their intellect. This apparent aimlessness of bourgeois music has in reality the very important function of supporting capitalism" (Grabs, in Maritz 1989:18).

Dit is veral die holistiese denke van die postmoderne era en die opkoms van musiekterapie gedurende die afgelope sestig jaar wat weer die waarde en essensie van musiek vir die mens wil beklemtoon. In geneeskunde en verskeie terapieẽ is daar groeiende besef van die terapeutiese krag van musiek. Byvoorbeeld, wat psigoterapie betref, maak Schelling (1989:101) die volgende uitspraak: "Muziek funktioneert als noodzaakakelijke tegenhanger van de heersende rationale benadering van de mens."

\subsection{Betekenis en kenmerke van musiek}

Gaston (in Peters 1987:49) beskryf musiek soos volg: "Music is the essence of humanness, not only because man creates it, but because he creates his relationship to it. Music is an essential and necessary function of man. It influences his behavior and condition and has done so for thousands of years". Daar is bree konsensus dat musiek op sigself nie betekenis dra nie, maar dat die betekenis van musiek gevind word in die hoorder se reaksie daarop (kyk Pavlicevec 1997:21; Storr 1992:25-48; Strydom 1994:63; Kloppers 1997:53). In 'n poging om al die verskillende menings oor die invloed van musiek op die mens te kombineer om tog 'n oorsigtelike opsomming te gee, noem ek 'n aantal kenmerke. 
- Musiek het die besondere vermoẽ om op meer as een vlak te kommunikeer. Of taalkundig gestel: om meer as een ding gelyktydig te sê. Musiek is terselfdertyd melodie, ritme, harmonie (of in eenstemmige musiek geìmpliseerde harmonie), vorm en dinamiek (toonsterkte).

Not only in poetry and music, but in all the arts, it is intuitively acceptable (and accepted by many writers of all periods) that the multi-level character of great art accounts for its numinous quality, and, as we have seen, the mechanisms of the brain make communication on many levels not only possible, but probable.

(McLauglin 1970:107)

Op al hierdie verskillende vlakke in die musiek is daar op dieselfde oomblik bewegings van spanning en oplossing.

Humans recognize patterns of flow, fluctuation or dissolution, of sustained or sudden tension and resolution, manifested in music. Moreover we are affected by these patterns: there exists an inextricable link between these patterns and human response to them, although this link is not a fixed one.

(Pavlicevic 1997:30)

- Musiek spreek die mens rasioneel en emosioneel aan (Storr 1992:27). Daar is deur navorsing bevind dat musiek en taal verteenwoordig word deur die twee hemisphere van die brein (Storr.1992:20). Alhoewel hierdie funksies oorvleuel, is taal oorwegend in die linkerbrein gesetel en musiek word oorwegend in die regterdeel van die brein ontvang. Die onderskeid is nie soseer tussen taal en musiek nie, maar tussen kognitiewe rasionaliteit en estetiese rasionaliteit. Waar woorde byvoorbeeld direk met ervarings verbind word, is die regterdeel aktief. Die linkerbrein werk met konsepte en logika. Storr (1992:24-37) gee interessante voorbeelde van hierdie navorsing. Een voorbeeld is dat wanneer die linkerdeel van 'n persoon se brein verdoof word, die persoon byvoorbeeld nie kan praat nie, 
maar wel kan sing. Dit is hoekom musiekterapie so suksesvol is met persone wat sukkel om hulleself verbaal uit te druk, byvoorbeeld gestremdes. Vir die doel van hierdie studie is die feit dat musiek op 'n kognitiewe (vorm) maar ook op ervaringsvlak (deur middel van die inhoud) die mens aanspreek, van groot belang. Daar is ook verder in navorsing aangetoon dat musiek breingolwe beïnvloed (Campbell 1997:66). Beta breingolwe (vibrasies tussen 14-20 hertz) is die gewone toestand van bewussyn. Verhoogde bewussyn en kalmte word weerspieel in alphagolwe (8-13 hertz). 'n Besondere hoe vlak van kreatiwiteit, meditasie en slaap word weerspieel in thetagolwe (4-7 hertz) en bewusteloosheid en diep meditasie deur deltagolwe (.5-3 hertz). Musiek met 'n polsslag van ongeveer 60 polsslae per minuut kan breingolwe van beta na alpha beweeg wat 'n verhoogde graad van bewussyn, kalmte en kreatiwiteit tot gevolg het. "Playing music at home, office or school can help to create a dynamic balance between the more logical left and the more intuitive right hemisphere - an interplay thought to be the basis of creativity" (Campbell 1997:66).

- Musiek kom tot stand in tyd. Volgens Verster (1989:11) is kunsvorms (skilder, beeldhou, argitektuur) se uitdrukkings staties. Musiek verteenwoordig egter die emosionele proses soveel te meer, omdat musiek, soos die werklikheid, altyd in konstante beweging is.

This is an art that lies in quite a different dimension. The visual arts give us the possibility to create formulations in space. They require visual effort for their perception and appreciation. The making and experiencing of music calls for quite another qualities and abilities than the visual arts, and the therapeutic possibilities are correspondingly of an entirely different nature.

(Frommer, in Verster 1989:12)

Hierdie kenmerk van musiek in tyd hou dus direk verband met 'n volgende kenmerk, naamlik die verband tussen musiek en emosie. Verster toon aan dat musiek (alhoewel dit nie emosie bevat nie) ' $n$ medium is waarin die mens met groot gemak sy of haar eie emosie kan projekteer. "Music is a tonal analogue of 
emotive life" (Langer, in Verster 1989:11). Pavlicevic (1997:19) meen dat alle musiek in verhouding met menslike emosie staan. Oaklander (1988) dui deur 'n omvattende studie aan hoe musiek in terapie met kinders gebruik kan word om hulle gevoelens en emosies weer te gee. Musiek kan dus as draer van menslike emosies dien.

- $\quad$ Storr (1992:90) besin in sy boek oor die vermos waaroor musiek beskik om die luisteraar bo hulle werklikheid en realiteit uit te lig. Dit is nie (soos Freud beweer) ' $n$ regressie na infantiliteit of soos wat die Marxiste sal reken opium vir die volk nie (Maritz 1989:29), maar die moontlikheid wat die luisteraar het om die gehoorervaring te struktureer en sin daaruit te maak. Op so 'n wyse het musiek die vermoë om (soos meditasie) die persoon te laat "ontsnap" uit 'n bepaalde realiteit.

\begin{abstract}
When we take part in music, or listen to an absorbing performance, we are temporarily protected from the input of other extemal stimuli. We enter a special, secluded world in which order prevails and from which the incongruous is excluded. It is not a regressive manoeuvre, but a temporary retreat which promotes a re-ordering process within the mind, and thus aids our adaptation to the external world rather than providing an escape from it.
\end{abstract}

(Storr 1992:105)

As die sosiale funksie van musiek dan in die hedendaagse gejaagde lewe verlore geraak het, dan kan musiek 'n ander funksie vervul. Musiek kan persoonlike gevoelens in die individu wakker maak waarvan die mens afgestomp geraak het. Musiek kan die persoon tot nadenke en introspeksie lei wat noodsaaklik is vir persoonlike groei en aktualisering. "Art, broadly speaking, is that which invites us into contemplation - a rare commodity in modern life" (Moore, in Müller en Heine 1998:164). In terapie is hierdie metode van retreat vandag uiters belangrik. Ansdell (1995:134) verwys spesifiek na musiekterapie wanneer hy aantoon dat

[t]herapy also makes use of the capacity of music to reach where other means of contact has failed. Related to the idea of music as "call" is that of "recall"; 
of how the order of music can recall a sense of order when the self is threatened by the chaos of the external world or from the disordering effects of illness or handicap.

'n Ander belangrike kenmerk kom ook uit hierdie aanhaling na vore, naamlik die vermoæ van musiek om 'n vorige gebeurtenis of ervaring op te roep. Omdat musiek so 'n sterk sintuiglike ervaring is (klanke wat gehoor word, vibrasies wat gevoel word), kan musiek deur middel van assosiasie onmiddellike ervarings uit die verlede oproep.

- 'n Verdere kenmerk van musiek is dat dit inhoud binne vorm/struktuur is. Musiekpedagoæ (kyk Storr 1992:122) meen dat musiek ervarings kan struktureer deurdat musiek se vorm en inhoud in die onderbewuste vasgelê word. Pavlicevic (1997:31) is van mening dat "we are susceptible to music because its forms already exist in our minds". Storr (1992:123) toon deur navorsing aan hoe vorm in musiek dag tot dag aktiwiteite in 'n veel groter mate struktureer as wat baie mense besef. Die kwessie oor vorm en inhoud in musiek is 'n netelige saak wat oor eeue in die musiekgeskiedenis en musiekfilosofie baie aandag gekry het. Dit sal vir die doel van hierdie studie nie verder hanteer word nie. Die verloop van musiek binne struktuur hou egter interessante terapeutiese moontlikhede in. Priestley (in Verster 1989:11), 'n musiekterapeut, meen dat die terapeut met musiek "can act as the leader of a guided tour into inner emotional territory. Safe because it is structured, the way has been signposted and trodden by thousands of others, nevertheless it is still an adventure."

- Die volgende kenmerk wat bespreek word, hou verband met die simboliese funksie van musiek. Die filosoof Schopenhauer (soos aangehaal in Storr 1992:140) meen dat die ander kunste 'n kopie is van die idee van die werklikheid self, maar dat musiek die idee self verteenwoordig. "Music, according to Schopenhauer, is understood immediately without any need to give any account of it or form any abstract conception of it." Musiek word dus 'n direkte simbool van die werklikheid wat ervaar word. 
...[W]e could just as well call the world embodied music as embodied will; this is the reason why music makes every picture, indeed every scene from real life and from the world, at once appear in enhanced significance, and this is, of course, all the greater, the more analogous its melody is to the inner spirit of the given phenomenon.

(Schopenhauer, in Storr 1992:141)

As ons hierdie stelling van musiek as kenmerk aanvaar, is die krisis (van 'n mens verwyder van die uitdrukkingsmoontlikheid van musiek) soveel groter. Begbie (1991:199) beskuldig Immanuel Kant vir die dilemma waarin postmoderne mense hulle bevind. "The overall logic of his aesthetics ... is one which leads towards alienation - of art from knowledge, of art from action, of artist from the physical world, of artist from fellow artist, of artist from society. As simbole en rituele helpende handelinge in 'n samelewing is om die werklikheid te hanteer, kan musiek as simbooldraer en vanwee die verwysende karakter bydra tot 'n "deelnemende bewussyn".

- 'n Laaste opmerking wat myns insiens relevant is in hierdie verbinding tussen musiek en pastoraat is dié van stilte in musiek. Twintigste-eeuse komponiste (bv John Cage), het beklemtoon dat stilte in musiek net so belangrik is as klank (Politoske 1984:486). Schelling meen "het ontbreken van zang en spel zegt meer dan duizend woorden (1989:81). Dit sê hy nadat hy ontleed het in welke mate musiek die Bybelse mens begelei het. Hy verwys spesifiek na Ps 137, waar die Israeliete in ballingskap hulle liere opgehang het. Stilte was hier 'n dieper vorm van uitdrukking as selfs musiek. Dit is eers wanneer ons musiek in sy volle betekenis, konsekwensies en funksionaliteit in ons lewens gebruik, dat ons die ware betekenis en waarde van stilte en swye sal begryp. 'n Saak wat hieraan verwant is, is dié van werklik luister. Musiek het in die Westerse samelewing 'n verbruikbare item geword, wat altyd maar op die agtergrond is, en slim gebruik word, byvoorbeeld oor Kerstyd, om verkope te bevorder. Mense het verleer om werklik te luister (na klank én na stilte). "The more I study listening, the more 
convinced I am that those who know how to listen are the exceptions" (Tomatis, in Campbell 1997:52).

Die uitdaging is om in 'n nuwe era met nuwe moontlikhede musiek weer deel te maak van ons ervaring en singewing van die werklikheid, sodat ons as heel mense kan leef en God kan verheerlik. Pastorale terapie kan myns insiens hierdie uitdaging aangryp en benut.

\section{Literatuurverwysings}

Adam, A K M 1995. What is postmodern biblical criticism? Minneapolis: Fortress.

Ansdell, G 1995. Music for Life: Aspects of creative music therapy with adult clients. London: Jessica Kingsley Publishers.

Begbie, J S 1991. Voicing creations praise: Towards a theology of the arts. Edinburgh: Clark.

Beukes, C J 2000. 'n Postmoderne redekritiek vir kerk en teologie. PhD-proefskrif, Universiteit van Pretoria.

Campbell, D 1997. The Mozart effect: Tapping the power of music to heal the body, strengthen the mind and unlock the creative spirit. New York: Avon Books.

Dingemans, G D J 1991. Als hoorder onder de hoorders. Kampen: Kok.

Dreyer, T F J 1981. Poimeniek: 'n Pastorale oriēntasie. Pretoria: HAUM.

Dreyer, T F J 1995. Implikasies van die kommunikatiewe handelingsteorie vir 'n prakties-teologiese perspektief op die ekklesiologie. HTS 51, 792-805.

Dreyer, T F J 1998. Spiritualiteit, identiteit en etos van die Nederduitsch Hervormde Kerk. HTS 54, 289-314.

Dreyer, Y 1998. Pastorale interaksie met vroue: 'n Prakties-teoretiese begronding. DDproefskrif, Universiteit van Pretoria.

Firet, J 1977. Het agogisch moment in het pastoraal optreden. Kampen: Kok.

Gerkin, C V 1991. Prophetic pastoral practice: A christian vision of live together. Nashville: Abingdon.

Heitink, G 1984. Pastoraat als hulpverlening. 2de Druk. Kampen: Kok. 
Hunter, R J et al 1990. Dictionary of pastoral care and counseling. Nashville: Abingdon.

Johannson, C M 1988. Music and ministry: A biblical counterpoint. 2nd edition. Massachusetts: Hendrickson.

Kloppers, E C \& Dreyer, T F J 1994. Liturgiese koorsang as wyse van kerklike verkondiging: 'n Prinsipiële besinning vanuit 'n hermeneuties-homiletiese perspektief. HTS 50, 583-607.

Kloppers, E C 1997. Liturgiese musiek as kommunikatiewe handeling in 'n postmoderne era. DTh-proefskrif, Universiteit van Suid-Afrika.

Louw, D J s a. Wetenskapsleer binne die teologie: Wetenskaplike navorsing as 'n teologiese vraagstuk. Ongepubliseerde lesing.

Louw, D J 1997. Pastoraat as ontmoeting en vertolking. Pretoria: Lux Verbi.

Maritz, J F 1989. Die Marxisties-Leninistiese musiekbeskouing. BMus Hons skripsie, Universiteit van Pretoria.

McFague, S 1987. Models of God. Philadelphia: Fortress.

McLaughlin, T 1970. Music and communication. London: Faber and Faber.

Müler, J C 1997. Om tot verhaal te kom. Pretoria: Lux Verbi.

Mûller, J C \& Heine, S 1998. Kunstige wetenskap of wetenskaplike kuns: Gedagtes oor pastorale terapie. NGTT 54(3), 162-168.

Oaklander, V 1988. Windows to our children. The Gestalt Highland: Journal Press.

Pavlicevic, M 1992. Mercedes Pavlivec on music therapy. S.A. Journal of Music Therapy 10(1), 2-3.

Pavlicevic, M 1997. Music therapy in context: Music, meaning and relationship. London: Jessica Kingsley Publishers.

Peters, J S 1987. Music therapy: An introduction. Illinois: Charles C Thomas Publisher. Pieterse, H J C 1993. Praktiese teologie as kommunikatiewe handelingsteorie. Pretoria: RGN-Uitgewers.

Politoske, D T 1984. Music. New Jersey: Prentice Hall.

Rossouw, G J 1993. Theology in a post-modern culture: Ten challenges. HTS 49, 894907.

Schelling, P 1989. Muziek en kerkewerk. S'Gravenhage: Uitgeverij Boekencentrum BV. 
Schoeman, M J 1990. Die herowering van 'n ou wysheid in 'n moderne konteks. HTS 46, 267-292.

Steenkamp, L J S 1996. Kerk en kultuur in 'n postmoderne samelewing. HTS 52, 746764.

Storr, A 1992. Music and the mind. New York: The Free Press.

Strydom, W M L 1994a. Besinning rondom die ontwerp van 'n Protestants-himnologiese estetika. Bloemfontein: Universiteit van die Vrystaat. (Acta Academica Supplementum 1.)

Strydom, W M L 1994b. "Sing nuwe sange, nuutgebore". Bloemfontein: NG Sendingpers.

Van Aarde, A G 1990. Holisme as 'n postmodernistiese filosofie in teologiese lig. HTS 46, 293-311.

Van Aarde, A G 1994. Kultuurimperialisme as 'n hermeneutiese dilemma: Eerste wêrreldse en Derde-wêreldse perspektiewe op Jesus as die Seun van God. HTS 50(1\&2), 345-367.

Van Aarde, A G 1995. Kerk en teologie op pad na die derde millennium: 'n Paradigmatiese verskuiwing van middelmatige aard. HTS 51, 3-12.

Van Huyssteen, J Wentzel 1996. The shaping of rationality in science and religion. HTS 52, 105-129.

Van Schalkwyk, G J 1998. 'n Sisteemparadigma vir musieksielkunde. PhD-proefskrif, Universiteit van Pretoria.

Verster, J 1989. Drie psigologies gefundeerde motiverings vir die gebruik van musiek as terapeutiese medium. SATMT 6(4), 10-13.

Wilson-Dickson, A 1997. A brief history of Christian music. 2nd edition. Oxford: Lion Publishing. 